\title{
Analysis of the Construction of Emergency Management System for Public Health Emergencies in Universities Based on the COVID-19 Epidemic
}

\author{
$\mathrm{Na} \mathrm{Ma}{ }^{1}$, Tao Chen ${ }^{1} *$, Zhihua $\mathrm{Li}^{2}$, Meng $\mathrm{Li}^{1}$ \\ ${ }^{I}$ Department of Engineering Physics Tsinghua University, Haidian District, Beijing, China \\ ${ }^{2}$ Department of Security Tsinghua University, Haidian District, Beijing, China \\ *Corresponding author. Email: $915383953 @ q q . c o m$
}

\begin{abstract}
In January 2020, the epidemic situation of the COVID-19 spread rapidly in China. Under the command of the Party Central Committee, universities achieved initial results. Throughout the transmission process of COVID-19, universities have responded with the timeliness and various measures, and found that there are still shortcomings and deficiencies in universities' response to public health emergencies. This article takes the COVID-19 epidemic situation as the background, and starts from the three key links of emergency emergency management, prevention and emergency preparation, monitoring and early warning, emergency handling and rescue, and puts forward suggestions for the emergency public health event emergency management system construction in universities.
\end{abstract}

Keywords: University, public health emergencies, emergency management system, COVID-19

\section{INTRODUCTION}

In December 2019, several cases of unexplained pneumonia with a history of exposure to the South China Seafood Market were found in Wuhan, Hubei Province. The outbreak of the epidemic coincided with the traditional Chinese New Year festival. Workers returned home and students were on holiday, resulting in COVID-19 was spread on a large scale. As of 13:16 on February 29, 2020, 79,389 cases were confirmed nationwide (including Hong Kong, Macao and Taiwan), and 2,348 died [1]. This is not the first time that China has faced a crisis of public health

\begin{abstract}
emergencies. Since the beginning of SARS in 2003, China has been continuously tested by bird flu, hand-foot-mouth disease, and HINI influenza.

Ensuring the safety and health of all school staff and students is the basic task of the school. In recent years, food poisoning, infectious disease outbreaks, and laboratory hygiene events have occurred frequently. Based on the COVID-19 epidemic, universities should systematically sort out the shortcomings and deficiencies exposed by the epidemic, establish and improve major epidemic prevention, control systems and mechanisms. Improve university emergencies Public health system.
\end{abstract}
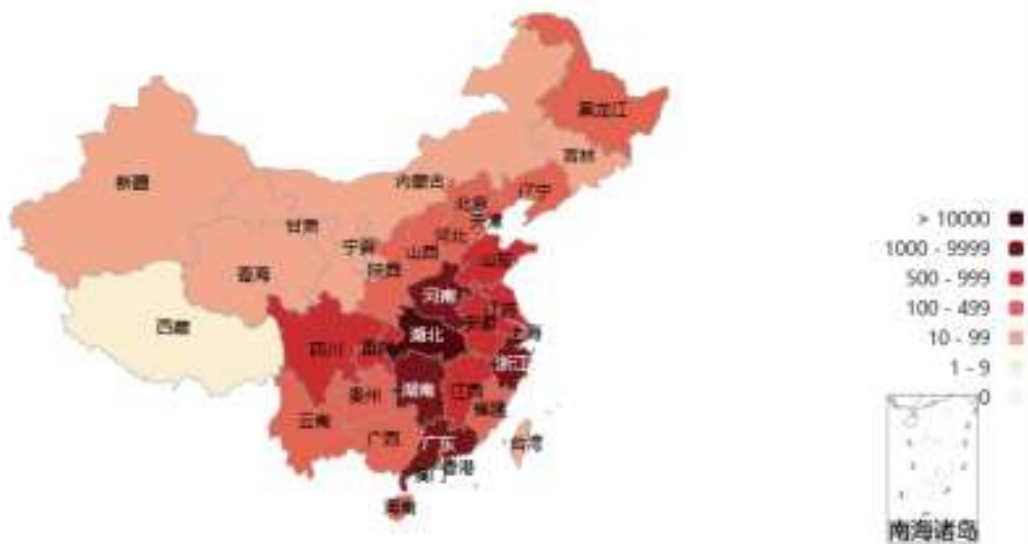

Figure 1 National (including Hong Kong, Macao and Taiwan) outbreak maps at 13:16 on February 29 


\section{THE STATUS OF PUBLIC HEALTH EMERGENCIES IN UNIVERSITIES}

\subsection{Analysis on the Prescription of COVID-19 Epidemic in Universities}

The first case of COVID-19 occurred in Wuhan on December 1, 2019, and the first case of COVID-19 was reported by Wuhan Health Commission on the 8th. At the beginning of the epidemic, it was in the unknown stage of "disease epidemic pathology "," whether the transmission is unknown" and "the cause of the disease is unknown ". On January 15, the CDC launched a first-level emergency response, and on the 20th, the State Council incorporated the COVID-19 into the statutory infectious disease, and Academician Zhong Nanshan confirms that the COVID-19 will be "person-to-person". On the 22th, the Ministry of Education responded to the state's call to immediately launch a contingency plan for public health emergencies in the education system. Since then, schools across the country have responded, issuing a series of notices such as delaying the spring school opening time and adjusting the spring teaching arrangements.
From the response decision-making time of units at all levels, there is obvious lag, which is because the core of our administrative system is bureaucracy, which is characterized by: hierarchy, Form, Division of Labor, Occupation, Dehumanization and Selection. And the response to the epidemic at all levels of the unit response hierarchy is due to the existence of bureaucracy "command-obedience" organizational form. Analysis and comparison, China 2003 SARS, the United States 2009 HINI, China 2020 COVID-19, the response process of infectious diseases can be divided into four stages: Disease Exploration, Information Black Box, Foreign Participation, Resolution. With the health system The human ability to deal with unknown diseases has increased, and the time to explore diseases has gradually decreased. In the Information Black Box stage is a unique place in China, in this stage the information is controlled by the government, this link can reflect the characteristics of the bureaucratic hierarchy in China, but through the 2003 SARS and the 2020 epidemic data of the COVID-19 epidemic, we can see that the comprehensive management ability of the government is increasing, the efficiency of the work is gradually improved, and the superiority of the socialist concentrated efforts to do the big things can also be reflected in the solution stage consumption of time.

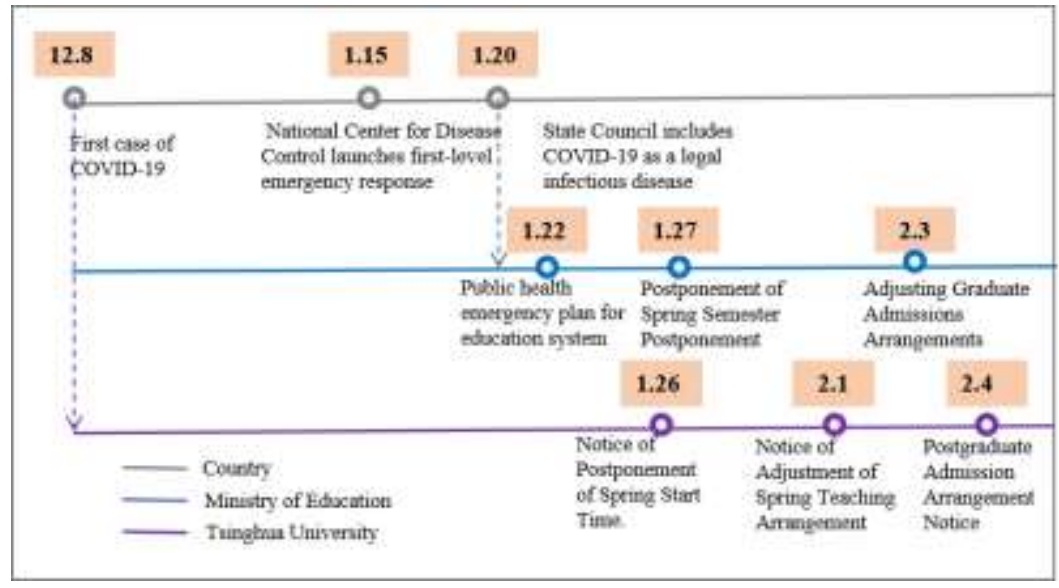

Figure 2 Timeline for important initiatives of COVID-19 Epidemic in units at all levels

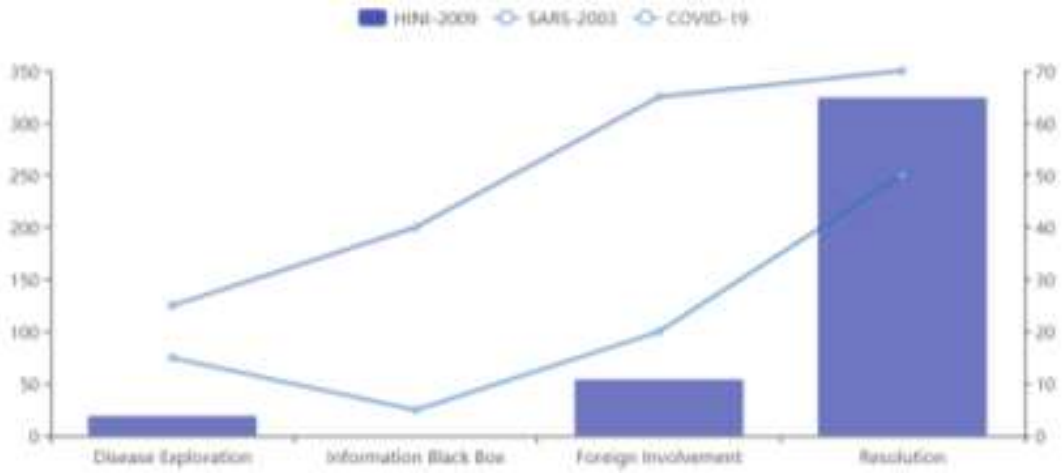

Figure 3 Four stages of infectious disease response 


\subsection{Analysis on the Measures to Combat the Epidemic of New Pneumonia in Colleges and Universities}

Beijing and Guangdong, as China's politically and economically developed regions, have a strong foundation for emergency response, so they have issued guidelines for prevention and control of outbreaks in universities in order to do a good job in preventing and controlling outbreaks in a down-to-earth manner[2,3]. Through comparative analysis, the two guidelines have made important arrangements in the epidemic prevention and control system, prevention and control work plan and system, information collection and monitoring, and various safeguard work. Taking Tsinghua University as an example, after receiving the notice, the school quickly set up a leading group for epidemic prevention and control, with the secretary of the party committee and the president of the school as the leader, comprehensive coordination of propaganda, academic workers, educational administration, logistics and other departments, and set up 13 special working groups (figure 4).

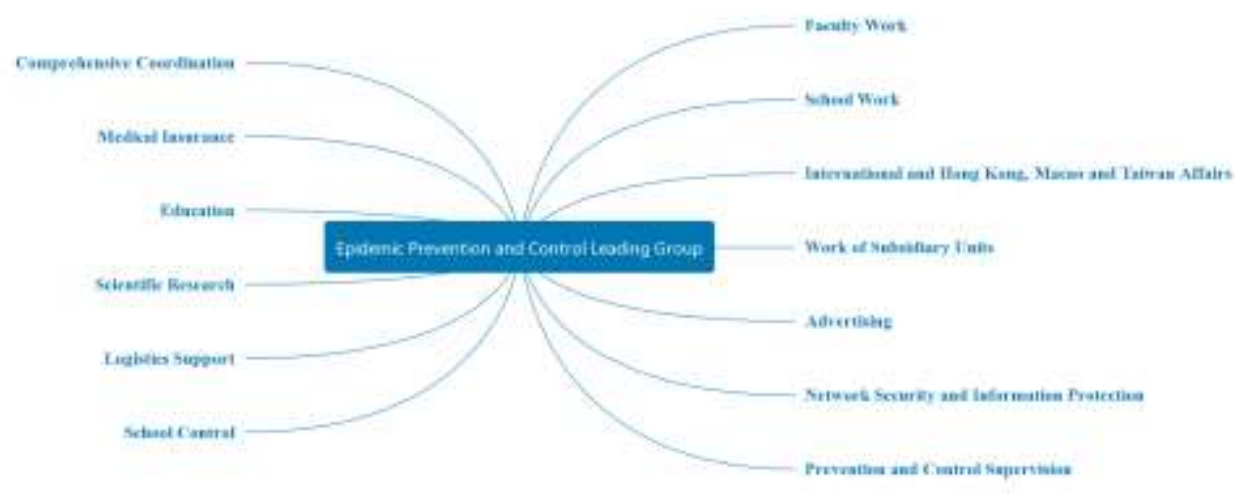

Figure 4 Tsinghua University leading group on prevention and control of COVID-19

Table 1 Guidelines for responding to the epidemic in universities in Beijing and Guangdong

\begin{tabular}{|c|c|c|}
\hline District & Beijing & Guangdong \\
\hline $\begin{array}{l}\text { Name of } \\
\text { Guide }\end{array}$ & $\begin{array}{l}\text { "Guidelines for the Prevention and } \\
\text { Control of Epidemic Situation in } \\
\text { Colleges and Universities in Beijing } \\
\text { (First Edition)" }\end{array}$ & $\begin{array}{c}\text { "Guide to the Prevention and Control } \\
\text { of New Pneumonia in Guangdong } \\
\text { Universities and Secondary } \\
\text { Vocational Schools (2nd Edition)" }\end{array}$ \\
\hline Publisher & $\begin{array}{l}\text { Beijing Municipal Committee of } \\
\text { Education }\end{array}$ & Guangdong Education Department \\
\hline $\begin{array}{l}\text { Time of } \\
\text { release }\end{array}$ & 29 January 2020 & 16 February 2020 \\
\hline $\begin{array}{l}\text { Primary } \\
\text { coverage }\end{array}$ & $\begin{array}{l}\text { 1.Establishment of a school leadership } \\
\text { system } \\
\text { 2.Standardize and improve measures for } \\
\text { epidemic prevention and control } \\
\text { 3.Strengthening Campus Environmental } \\
\text { Hygiene Management } \\
\text { 4.Comprehensively strengthen campus } \\
\text { environmental sanitation management } \\
\text { 5.Effectively strengthen emergency } \\
\text { support }\end{array}$ & $\begin{array}{l}\text { 1. Scope of application } \\
\text { 2. Target requirements } \\
\text { 3. Principles and main measures } \\
\text { 4. Outbreak control measures }\end{array}$ \\
\hline
\end{tabular}




\subsection{Lack of Emergency Management System for Public Health Emergencies in Universities}

At the beginning of this century, the United States and other western countries began to establish a series of early warning mechanisms and relevant laws and regulations to prevent public health emergencies, set up special institutions and departments to professionally manage public health emergencies on campus, and publicize crisis theory and knowledge of coping. For example, Eugene, an American scholar, introduced in his book "Campus Crisis Management: Planning, Prevention and Recovery" the university emergency team construction and training, organizational resilience and so on. The U.S. Department of Education issued a "Use of Crisis Plans: A Guide to Schools and Communities" in May 2003 to help colleges and universities develop emergency management for public health emergencies Policy guide[4].

Compared with other countries, China has formulated or revised the Regulations on Emergency Management of Public Health Emergencies, the Law of the People's Republic of China on Emergency Response to Public Health Emergencies, the Law of the People's Republic of China on Prevention and Control of Infectious Diseases and the Food Safety Law of the People's Republic of China, etc. And a large number of research results emerged after SARS in 2003 to improve the emergency management system for public health emergencies in universities, but the following problems still exist

\subsubsection{National security system imperfect}

On April 17, 2018, the first meeting of the 19th Central National Security Committee was strongly adjusted, and it was necessary to fully implement the overall national security concept and put forward 11 kinds of national security. Because the epidemic was caused by biological factors, on February 14, 2020, the central government held the 12th meeting of the Central Committee for Comprehensive deepening Reform to propose to integrate bio-safety into the national security system, and colleges and universities should also integrate bio-safety into the school safety system to systematically plan risk prevention and control and comb the management system.

\subsubsection{Lack of attention to the construction of emergency management system for public health emergencies}

Compared with the sudden events with high frequency of traffic safety and laboratory safety in universities, public health events have the characteristics of distributed differences, which makes the risk of dangerous situations less likely, so the risk of public health events is less than the acceptable level of risk, and it will not attract the attention of schools.

Risk size $(R)=$ likelihood of risk occurring $(p) \times$ severity of risk $(f)$

\subsubsection{Lack of guidance in the construction of emergency system for public health emergencies}

In this epidemic situation, the ability of universities to deal with the epidemic is uneven, the operation mechanism is lack of systematization, mainly reflected in the weak ability of dynamic monitoring of diseases, the lack of knowledge of public health prevention and control, the lack of understanding of the epidemic situation, the lack of emergency system and resource guarantee, the lack of linkage mechanism between departments, the formalization of emergency drills, the lack of operation, the lack of staff and students' propaganda and education, and the lack of crisis consciousness.

\section{SUGGESTIONS ON THE CONSTRUCTION OF EMERGENCY MANAGEMENT SYSTEM FOR UNIVERSITY PUBLIC HEALTH EMERGENCIES}

\subsection{Prevention and Emergency Preparedness}

We will resolutely implement the principle of "prevention-oriented" in health work and adhere to the principle of standing up to the standards. Improve the organizational framework of prevention and control leadership, clarify the responsibilities of the main body, improve the ability of joint defense and control, and ensure that the area of responsibility "no dead corner ". To formulate the general emergency plan for public health emergencies in our school, to ensure that the plan is operable and comprehensive, and to ensure that all procedures are regulated. To ensure sufficient manpower, material and financial resources, and establish a material reserve system and a personnel information base. Strengthen the education science and personnel training, strengthen the risk awareness, cultivate good health and hygiene habits. Strengthen the construction of public health personnel, strictly monitor the admission of practitioners, treatment protection, assessment machine System.

\subsection{Monitoring and Early Warning}

Establish a relatively independent public health information system. According to the seasonal characteristics of the development of the region and disease, make a dynamic 
public health event risk list, divide the risk area, rely on man-machine monitoring of risk, and improve the study of major public health risks. Set the risk acceptance threshold, set the early warning classification for the existence of risk, and do a good job of reporting mechanism based on the early warning level, so as to achieve "early discovery, early warning, early control ".

\subsection{Emergency Disposal and Rescue}

In the event of sudden public health incidents, the emergency response should be started quickly to ensure that the organization and leadership are in place, the system guarantee is in place, and the personnel strength is in place. Do a good job of information reporting, information disclosure, to ensure smooth communication channels, to multi-level, high-density release of authoritative information. Do a good job of propaganda, education and public opinion guidance, strengthen public opinion monitoring, carry forward positive energy, and avoid anxiety and panic psychology. Carry out mass prevention and control, unified deployment, maintain normal order in schools, and avoid secondary disasters. Standardize and improve the specific measures of prevention and control work, such as strengthening school gate control measures, personnel management, centralized quarantine observation area management, campus environmental hygiene management, etc.

\section{ACKNOWLEDGMENT}

This research was financially supported by the Tsinghua University's Independent Scientific Research Plan "School Security System Construction Planning Research" (20191081202).

\section{REFERENCES}

[1] Information on http://www.nhc.gov.cn/

[2] Information on http://jw.beijing.gov.cn/

[3] Information on http://edu.gd.gov.cn/

[4] Yun-xia YE. Analysis of Public Health Emergency Management in Universities [D]. East China University of Science and Technology (2014)

[5] Zai-xiang TAN, Song-ting WU and Xiao-ping WU.Revelation and Enlightenment of Emergency Management System for Public Health Incidents in the United States and Japan-Also on China's New Coronavirus Pneumonia Epidemic Response [J] .Journal of Health Economics , (2020): 1-6. 